\title{
Calcium release induced by 2-pyridinecarboxaldehyde thiosemicarbazone and its copper complex contributes to tumor cell death
}

\author{
YUN FU ${ }^{1 *}$, YOUXUN LIU $^{1 *}$, JIANGANG WANG ${ }^{2}$, CUIPING LI $^{1}$, SUFENG ZHOU $^{1}$, \\ YUN YANG ${ }^{1}$, PINGXIN ZHOU ${ }^{1}$, CHENGBIAO LU ${ }^{2}$ and CHANGZHENG LI ${ }^{1,3}$ \\ Departments of ${ }^{1}$ Molecular Biology and Biochemistry and ${ }^{2}$ Pathophysiology, Xinxiang Medical University; \\ ${ }^{3}$ Henan Collaborative Innovation Center of Molecular Diagnostics and Laboratory of Medicine, \\ Xinxiang, Henan 453003, P.R. China
}

Received July 3, 2016; Accepted August 22, 2016

DOI: $10.3892 /$ or.2017.5395

\begin{abstract}
Thiosemicarbazones display significant antitumor activity and their copper complexes also exhibit enhanced biological activities in most situations, but the underlying mechanism is poorly understood. Therefore, investigation of the mechanism involved in the change upon chelation is required to extend our understanding of the effects of thiosemicarbazones. In the present study, the inhibitory effect of 2-pyridinecarboxaldehyde thiosemicarbazone (PCT) and its copper complex (PCT-Cu) on cell proliferation was investigated. The copper chelate exhibited a 3- to 10 -fold increase in antitumor activity (with an $\mathrm{IC}_{50}<5 \mu \mathrm{M}$ ). The results showed that both PCT and PCT-Cu induced reactive oxygen species (ROS) generation in vitro and in vivo, caused cellular DNA fragmentation, depolarization of the mitochondrial membrane and cell cycle arrest. Western blotting showed that both PCT and PCT-Cu induced apoptosis. Upregulation of GRP78 in HepG2 cells following treatment with the agents indicated that endoplasmic reticulum (ER) stress occurred. Furthermore calcium release was revealed in this study, suggesting that PCT and PCT-Cu disturbed calcium homeostasis. It was noted that PCT-Cu sensitized thapsigargin-stimulated calcium release from the ER, which was correlated with the ROS level they induced, implying that the antitumor activity of PCT and PCT-Cu partly stemmed from calcium mobilization, a situation that was reported in few studies. Our findings may significantly contribute to the
\end{abstract}

Correspondence to: Dr Changzheng Li, Department of Molecular Biology and Biochemistry, Xinxiang Medical University, 601 Jinsui Road, Xinxiang, Henan 453003, P.R. China

E-mail: changzhenl@yahoo.com

${ }^{*}$ Contributed equally

Key words: 2-pyridinecarboxaldehyde thiosemicarbazone, cell cycle arrest, ROS, endoplasmic reticulum stress, calcium mobilization understanding of the anti-proliferative effect of the derivatives of thiosemicarbazones along with their antitumor mechanism.

\section{Introduction}

Thiosemicarbazones have received considerable attention due to their numerous biological activities, such as antibacterial, antitumor and anti-inflammatory properties (1-3), and their biological activities are involved in the i) inhibition of ribonucleoside diphosphate reductase; ii) creation of lesions in the DNA strand by oxidative rupture; and iii) binding to the nitrogen bases of nucleic acid, disturbing replication (4-6). Moreover, the planar thiosemicarbazone derivatives also display an intercalating function towards DNA and target DNA topoisomerase (7). Some of them can induce cell cycle delay (8). It has been demonstrated that excellent biological activities stem from the formation of iron (or copper) complexes in vivo that are redox-active species. Thereby one hypothesis proposes that these complexes can promote the Fenton-like reaction and produce significant amounts of hydroxyl radicals that interfere with normal cell functions (9). However, details behind this action are still not fully understood.

The unfolded protein response (UPR) is a cellular stress response related to the endoplasmic reticulum (ER), which can be triggered by a wide variety of cellular events, such as accumulation of misfolded/unfolded proteins, or changes in the redox environment of the ER and disruption of $\mathrm{Ca}^{2+}$ homeostasis (10). It has been demonstrated that $\mathrm{Cu}^{2+}$ thiosemicarbazone complexes generate oxidative stress, whereas the ligands do not (11-14). Similarly this is the case for 2-pyridinecarbaldehyde $\mathrm{N}, \mathrm{N}$-bis(2-pyridinylmethyl)thiosemicarbazone (11). However, the metal-free thiosemicarbazones 3-AP and 3-AP-Me display a different approach in the induction of ER stress that is reactive oxygen species (ROS) independent (15). These studies revealed that thiosemicarbazones have diverse mechanisms of action.

Calcium ions are important for cellular signaling and display allosteric regulatory effects on many enzymes and proteins. Therefore the intracellular $\mathrm{Ca}^{2+}$ concentration $\left(\left[\mathrm{Ca}^{2+}\right]_{\mathrm{i}}\right)$ plays a key role in cellular life $(16) .\left[\mathrm{Ca}^{2+}\right]_{\mathrm{i}}$ is 
adjusted by $\mathrm{Ca}^{2+}$ entry and $\mathrm{Ca}^{2+}$ release from intracellular stores. In non-excitable cells, the inositol-1,4,5-trisphosphate $\left(\mathrm{IP}_{3}\right)$-sensitive ER $\mathrm{Ca}^{2+}$ stores contribute to the increase in $\left[\mathrm{Ca}^{2+}\right]_{\mathrm{i}}(17) . \mathrm{IP}_{3}$ causes the release of $\mathrm{Ca}^{2+}$ from the ER. Reverse discharge of $\mathrm{Ca}^{2+}$ stores often triggers $\mathrm{Ca}^{2+}$ entry, refilling $\mathrm{Ca}^{2+}$ stores. Although the derivatives of thiosemicarbazone induce ER stress, the effect of related $\mathrm{Ca}^{2+}$ flux on anti-proliferation has received less attention. In the present study, the antitumor mechanisms of 2-pyridinecarboxaldehyde thiosemicarbazone (PCT) and its copper complex (PCT-Cu) were preliminarily investigated, revealing that ROS production plays an important role in the inhibition of proliferation, DNA fragmentation and apoptosis. The upregulation of ER stress molecular marker, GRP78, indicated the involvement of ER stress in the inhibition of proliferation. Furthermore, the investigated thiocarbazones had the distinct ability to sensitize the target, thapsigargin, a $\mathrm{Ca}^{2+}$ ATPase inhibitor (18). The present study suggests that the antitumor mechanism of thiosemicarbazones may also be involved in calcium mobilization, which has not yet been elucidated.

\section{Materials and methods}

Materials. All reactants and solvents were AR grade. MTT, ethidium bromide (EB), RPMI-1640 and agarose were purchased from Sigma-Aldrich (St. Louis, MO, USA). LC3 and GRP78 antibodies were obtained from ProteinTech Group, Inc. (Wuhan, China). Caspase- 3 and -8, $\beta$-actin, Bax and $\mathrm{Bcl}-2$ were purchased from Boster Biological Technology (Wuhan, China).

Preparation of PCT. PCT was prepared as previously described (19). To test whether PCT can react with copper, we mixed a solution of PCT with a solution of $\mathrm{CuCl}_{2}$ at 1:1 molar ratio, and subsequently, a marked color change was observed (20). Its copper complex was prepared by mixing equivalent amounts of PCT (in DMSO) and $\mathrm{CuCl}_{2}$ (in water). ${ }^{1} \mathrm{H}$ NMR of PCT (ppm): $7.41(\mathrm{t}, 1 \mathrm{H}), 7.87(\mathrm{t}, 1 \mathrm{H}), 8.18(\mathrm{~s}, 1 \mathrm{H}), 8.30(\mathrm{~d}, 1 \mathrm{H}), 8.37(\mathrm{~s}, 1 \mathrm{H})$, 8.59 (d, 1H), 11.67 (s, 1H); $m / z, 181.0600$.

Cytotoxicity assay (MTT assay). The stock solution of PCT was prepared in DMSO and it was diluted to the required concentration with culture medium when used. Human colorectal carcinoma cell line (HCT-116) and liver carcinoma cells (HepG2) were cultured in RPMI-1640 medium supplemented with $10 \%$ fetal calf serum (FCS) and antibiotics. The cells collected from exponential-phase $\left(1 \times 10^{4} / \mathrm{ml}\right)$ were seeded equivalently into 96-well plates and various amounts of PCT were added after the cells adhered. Following a 48-h incubation at $37^{\circ} \mathrm{C}$ in a humidified atmosphere of $5 \% \mathrm{CO}_{2}, 10 \mu \mathrm{l}$ MTT solution $(1 \mathrm{mg} / \mathrm{ml})$ was added to each well, followed by further incubation for $4 \mathrm{~h}$. The cell culture was removed by aspiration and $100 \mu \mathrm{l}$ DMSO was added to each well to dissolve the formazan crystals. The assessment of the absorbances of the solution that were related to the number of live cells was performed on a microplate reader (MK3; Thermo Fisher Scientific) at $570 \mathrm{~nm}$. Percentage of growth inhibition was defined as the percentage of absorbance inhibition within an appropriate absorbance in each cell line. The same assay was performed in triplicate.
ROS detection. $\mathrm{H}_{2} \mathrm{DCF}-\mathrm{AM}$ was converted to dichlorofluorescein (DCF) according to a previously described method (21). Briefly, $0.25 \mathrm{ml}$ of $2 \mathrm{mM} \mathrm{H}_{2}$ DCF-AM in absolute ethanol was added to $2.0 \mathrm{ml}$ of $10 \mathrm{mM} \mathrm{NaOH}$ and allowed to stand at room temperature for $30 \mathrm{~min}$. The hydrolysate was then neutralized with $10 \mathrm{ml}$ of $25 \mathrm{mM}$ sodium phosphate buffer ( $\mathrm{pH} 7.2$ ), and kept on ice for use. Reaction mixtures contained $0.4 \mu \mathrm{M}$ DCF in $50 \mathrm{mM}$ sodium phosphate buffer ( $\mathrm{pH} \mathrm{7.4)} \mathrm{and} \mathrm{the} \mathrm{eventual}$ addition of $25 \mu \mathrm{l}$ of $1 \mathrm{mM} \mathrm{NH}_{4} \mathrm{FeSO}_{4}$ or $1 \mathrm{mM} \mathrm{PCT}$ in a total volume of $4.0 \mathrm{ml}$. After the addition of $0.2 \mathrm{ml}$ of $4 \mathrm{mM} \mathrm{H}_{2} \mathrm{O}_{2}$, the fluorescence was assessed on an FC-960 spectrofluorimeter (excitation at $488 \mathrm{~nm}$ and emission at $525 \mathrm{~nm}$ ). The measurements were conducted at room temperature.

The intracellular ROS production was assessed as recommended by the manufacturer (Beyotime Institute of Biotechnology, Beijing, China). Approximately 1x10 ${ }^{6}$ HepG2 cells were collected and washed by PBS. The cell pellets were re-suspended in DCFH-DA containing serum-free culture medium and incubated for $30 \mathrm{~min}$. The stained cells were re-collected and washed with serum-free culture medium. Then $100 \mu \mathrm{l}$ of the cells were transferred to PCR tubes and the test compound was added. Following a 1-h incubation, the cell suspension was used directly for ROS determination on an FC-960 spectrofluorimeter by excitation at $488 \mathrm{~nm}$ and emission at $525 \mathrm{~nm}$.

Comet assay. The comet assay was adapted from a previous study as described (22). HepG2 cells were exposed to the investigated agents (12 and $25 \mu \mathrm{M}$ for the PCT or 2.5 and $5 \mu \mathrm{M}$ for PCT-Cu complex) for a $24-\mathrm{h}$ incubation in a humidified atmosphere of $5 \% \mathrm{CO}_{2}$. The cells were harvested by centrifugation after trypsinization and then embedded in $0.5 \%$ low-melting-point agarose at a final concentration of $1 \times 10^{4}$ cells $/ \mathrm{ml}$. A $20 \mu \mathrm{l}$ aliquot of this cellular suspension was then spread onto duplicate frosted slides that had previously been covered with $1 \%$ normal melting point agarose as a basal layer. Slides were allowed to solidify for $10 \mathrm{~min}$ at $4^{\circ} \mathrm{C}$ before being placed in lysis buffer for $1 \mathrm{~h}[2.5 \mathrm{M} \mathrm{NaCl}$, $0.1 \mathrm{M}$ ethylenediaminetetraacetic acid (EDTA), 0.01 M Tris, $1 \%$ Triton $\mathrm{X}-100,10 \%$ DMSO, pH 10.0]. After lysis, the slides were transferred into an alkaline buffer for $40 \mathrm{~min}(0.001 \mathrm{M}$ EDTA, $0.3 \mathrm{M} \mathrm{NaOH}, \mathrm{pH}>13.0$ ) to allow the DNA to unwind before migration at $0.66 \mathrm{~V} / \mathrm{cm}$ and $300 \mathrm{~mA}$ for $30 \mathrm{~min}$. All these steps were performed in the dark. After neutralization in $0.4 \mathrm{M}$ Tris- $\mathrm{HCl} \mathrm{pH} \mathrm{7.4,} \mathrm{the} \mathrm{slides} \mathrm{were} \mathrm{stained} \mathrm{with} \mathrm{EB}$ $(20 \mu \mathrm{g} / \mathrm{ml})$ and covered with a cover-slip. The images were captured using fluorescence microscopy.

Flow cytometric assessment of the mitochondrial membrane permeability. HepG 2 cells $\left(1 \times 10^{5}\right)$ were seeded in a 6 -well plate and incubated for $24 \mathrm{~h}$ at $37^{\circ} \mathrm{C}\left(5 \% \mathrm{CO}_{2}\right)$, then the medium was replaced with fresh medium and supplemented or not (control) with the agents (5 and $10 \mu \mathrm{M}$ for PCT or 2.5 and $5 \mu \mathrm{M}$ for PCT-Cu complex). After $24 \mathrm{~h}$ of incubation, the cells were harvested with trypsin, followed by washing with PBS, fixed in $70 \%$ ethanol and stored at $-20^{\circ} \mathrm{C}$. The cells were stained using $20 \mathrm{ng} / \mathrm{ml}$ of rhodamine 123 (R123) in PBS for $30 \mathrm{~min}$. Flow cytometry (Becton-Dickinson, Franklin Lakes, NJ, USA) was employed to perform analysis of the depolarization of the mitochondrial membrane as described in a previous study (23). 
Cell cycle analysis. HepG2 cells $\left(1 \times 10^{5}\right)$ were treated as previously described in the flow cytometric assessment of the mitochondrial membrane permeability except that they were stained using a different dye. The cellular nuclear DNA was stained using propidium iodide (PI). Briefly, after the removal of 70\% ethanol, the cells were washed with PBS and then suspended in $0.5 \mathrm{ml}$ PBS containing $50 \mu \mathrm{g} / \mathrm{ml} \mathrm{PI}$ and $100 \mu \mathrm{g} / \mathrm{ml}$ RNase. The cell suspension was incubated at $37^{\circ} \mathrm{C}$ for $30 \mathrm{~min}$. DNA flow cytometry was performed in duplicate with a FACSCalibur flow cytometer (Becton-Dickinson). For each sample 10,000 events were collected and fluorescent signal intensity was recorded and analyzed by CellQuest and Modifit (Becton-Dickinson).

$P C T$ and PCT-Cu induce regulation of apoptosis and ER stress-related proteins. Total RNA was extracted from the cells that were exposed to the investigated agents for $24 \mathrm{~h}$ by TRIzol reagent (Sangon Biotech Co., Ltd., Shanghai, China) according to the manufacturer's recommendation. Two micrograms of total RNA were used for reverse transcription in a total volume of $20 \mu 1$ with the M-MLV reverse transcriptase system (LifeFeng Biological Technology Corp., Shanghai, China). One microliter cDNA was subsequently amplified in a total volume of $20 \mu \mathrm{l}$ using the $2 \mathrm{X}$ Taq PCR kit (LifeFeng Biological Technology Corp.). The sense and antisense primers (Generay Bioengineering Co. Ltd., Shanghai, China) for $\beta$-actin were 5'-ACACTGTGCCCATCTACGAGG-3' and 5'-CGGACTCGTCATACTCCTGCT-3' (615 bp) and were used as an internal control; the sense and antisense primers for caspase-8 were 5'-AAGTTCCTGAGCCTGGACTACAT-3' and 5'-ATTTGAGCCCTGCCTGGTGTCT-3' (227 bp); for caspase-3 they were 5'-GAAGCGAATCAATGGACTCTGG-3' and 5'-ACATCACGCATCAATTCCACAA-3' (241 bp); for Bcl-2 they were 5'-TTACCAAGCAGCCGAAGA-3' and 5'-TCCCTCCTTTACATTCACAA-3' (309 bp); for Bax they were 5'-TTTTGCTTCAGGGTTTCATC-3' and 5'-GGCCTT GAGCACCAGTTT-3' (299 bp), respectively. The RT-PCR was conducted on a Nexus Gradient Mastercycler (Eppendorf AG, Hamburg, Germany). The cycling conditions were as follows: $94^{\circ} \mathrm{C}$ for $3 \mathrm{~min}$, followed by 30 cycles of $94^{\circ} \mathrm{C}$ for $30 \mathrm{sec}, 53-56^{\circ} \mathrm{C}$ for $30 \mathrm{sec}$, and $72^{\circ} \mathrm{C}$ for $1 \mathrm{~min}$ and a final extension of $72^{\circ} \mathrm{C}$ for $10 \mathrm{~min}$. PCR products were separated on an $1.5 \%$ agarose gel viewed by EB staining. These data were acquired with a Tocan 360 gel imager (version 3.2.1 software).

The related gene expression at the protein levels was monitored by western blotting. Briefly, the $1 \times 10^{7} \mathrm{HepG} 2$ cells that were treated with or without the agents were scraped off in lysis buffer (50 mM Tris-HCl, pH 8.0, $150 \mathrm{mM} \mathrm{NaCl}, 1.0 \%$ NP-40, $10 \%$ glycerol and protease inhibitors) and subjected to further incubation on ice, following spin down by centrifugation at $14,000 \mathrm{x}$ g. The clear supernatant was collected and stored at $-80^{\circ} \mathrm{C}$. After determination of the protein concentration by Bio-Rad DC protein assay, $30 \mu \mathrm{g}$ of proteins were separated on a $13 \%$ sodium dodecyl sulfate-polyacrylamide gel at $200 \mathrm{~V}$ for $2.5 \mathrm{~h}$. Then the separated proteins were subsequently transferred onto a PVDF membrane at $60 \mathrm{~V}$ for $1 \mathrm{~h}$. The membrane was washed three times with Tris-buffered saline (TBS) and then blocked for $2 \mathrm{~h}$ in TBS containing $0.1 \%$ Tween-20 and 5\% nonfat skimmed milk. The membrane was incubated at $4^{\circ} \mathrm{C}$ overnight with the primary monoantibody used at a dilution of
1:300 in TBST (TBS plus 0.1\% Tween-20). The membrane was washed several times with TBST and was subsequently incubated with an HRP-conjugated secondary antibody (1:2,000 in TBST) for $1 \mathrm{~h}$ at room temperature. Following another wash of the membrane with TBST, the protein bands were detected using ECL solution (Boster Biological Technology).

$\mathrm{Ca}^{2+}$ imaging. $\left[\mathrm{Ca}^{2+}\right]_{\mathrm{i}}$ in the cultured HepG2 cells was assessed using the membrane-permeant acetoxymethyl (AM) ester of Fura-2 (Dojindo Laboratories, Kumamoto, Japan) dissolved in DMSO. For the assessment of calcium in the static state, HepG2 cells were treated with PCT $(6 \mu \mathrm{M})$ or PCT-Cu $(3 \mu \mathrm{M})$ overnight and then the cells were washed with FCS-free RPMI-1640, and loaded with $1 \mu \mathrm{M}$ Fura-2/AM for $\sim 30 \mathrm{~min}$ at $37^{\circ} \mathrm{C}$ in a $5 \% \mathrm{CO}_{2}$ atmosphere incubator, followed by three washes with PBS. The calcium signals were then assessed from the selected cells. Transient calcium signal measurements were conducted as previously described (24). Briefly the cells were pre-treated with or without (control) PCT $(6 \mu \mathrm{M})$ or PCT-Cu $(1.5$ or $3 \mu \mathrm{M}$ ) for $\sim 5 \mathrm{~min}$. Thapsigargin (at a final concentration of $1 \mu \mathrm{M}$ ) was added to stimulate calcium release from the ER stores. Fluorescent images from selected HepG2 cells were observed with a $x 40$ water-immersion objective lens and an upright microscope (FN1; Nikon, Tokyo, Japan). The excitation light at 340 and $380 \mathrm{~nm}$ for Fura-2 experiments was provided by a monochromator (Cairn Research, Ltd.), while the emission filter $(510 \mathrm{~nm})$ was placed in the filter wheel located in front of the camera. Fluorescent images were obtained (F340 and F380) every second using a cooled CCD camera (iXON DU-897; Andor Technology Ltd.). All equipment was used in combination with MetaFluor software (Molecular Devices, Inc., Downingtown, PA, USA).

\section{Results}

Cytotoxicity of PCT and its copper complex. It has been shown that derivatives of PCT display significant inhibition of proliferation against L1210 leukemia cell lines (25). To elucidate the underlying mechanism, the inhibitory effects of PCT and its copper complex (Fig. 1A) against the proliferation of tumor cell lines was determined. The dose-response curves of PCT determined against HepG2 and HCT-116 cell lines are depicted in Fig. 1B and C. As shown, PCT exhibited significant growth inhibition in $\mathrm{HepG} 2\left(\mathrm{IC}_{50}, 5.1 \pm 1.2 \mu \mathrm{M}\right)$ and moderate inhibition for HCT-116 cells $\left(\mathrm{IC}_{50}, 29.5 \pm 1.5 \mu \mathrm{M}\right)$. Due to the chelating ability of PCT, its copper complex was prepared (see Materials and methods) and tumor cell proliferation was evaluated. Notably, PCT-Cu exhibited excellent antitumor activities with an $\mathrm{IC}_{50}$ of $1.7 \pm 0.6 \mu \mathrm{M}$ for HepG2 and $2.7 \pm 0.5 \mu \mathrm{M}$ for HCT-116 cells, respectively.

PCT and its copper complex induce ROS generation. The production of ROS from iron chelators is an important antitumor mechanism of drugs, and it is correlated with the cytotoxicity of many drugs. Thus an ROS generation assay was performed to probe the possibility in vitro and in vivo. As shown in Fig. 2A, PCT had the ability to induce ROS formation in a Fenton-like reaction, indicating that the PCT-Fe ${ }^{2+}$ complex was a redox-active species. In contrast to PCT- $\mathrm{Fe}^{2+}$, PCT- $\mathrm{Cu}^{2+}$ in the presence of $\mathrm{H}_{2} \mathrm{O}_{2}$ produced more ROS in 
A

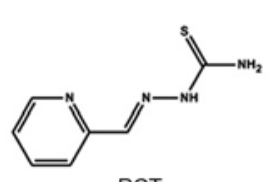

PCT

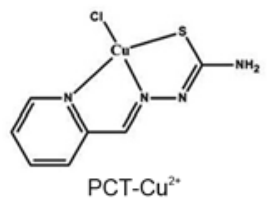

PCT-Cu+
B

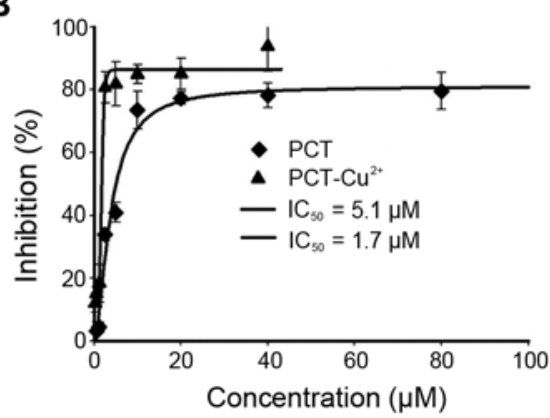

C

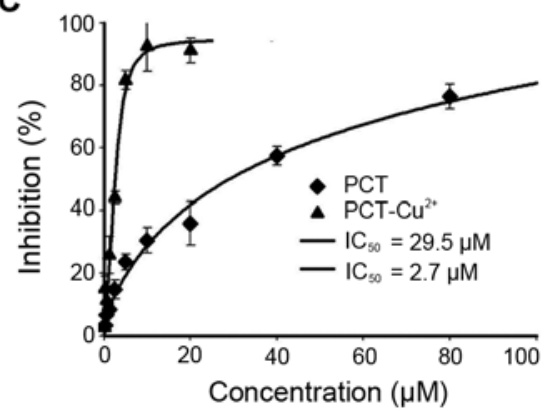

Figure 1. The chemical structure of PCT and its copper complex (PCT-Cu) and their inhibitory effects on cell proliferation. (A) Chemical structure of PCT and the PCT-copper complex. (B) Cytotoxicity of PCT and PCT-Cu against the HepG2 cell line $\left(\mathrm{IC}_{50}, 5.1 \pm 1.2 \mu \mathrm{M}\right.$ for PCT; $1.7 \pm 0.6 \mu \mathrm{M}$ for PCT-Cu. (C) Cytotoxicity of PCT and PCT-Cu against the HCT116 cell line ( $\mathrm{IC}_{50}, 29.5 \pm 1.5 \mu \mathrm{M}$ for PCT; $2.7 \pm 0.5 \mu \mathrm{M}$ for PCT-Cu). PCT, 2-pyridinecarboxaldehyde thiosemicarbazone.

A

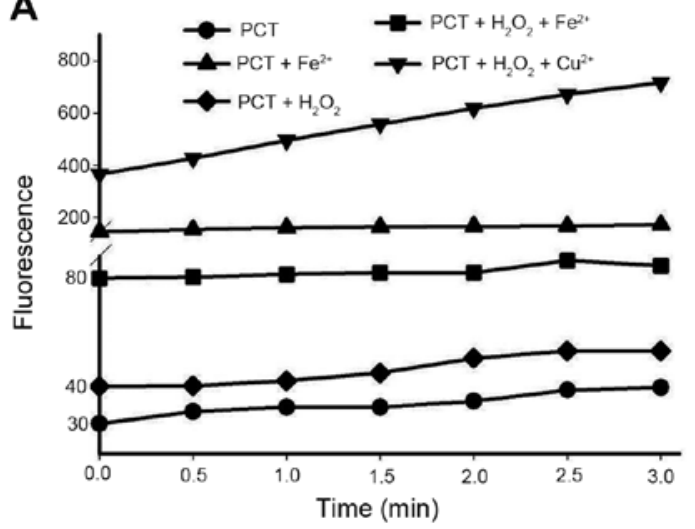

B

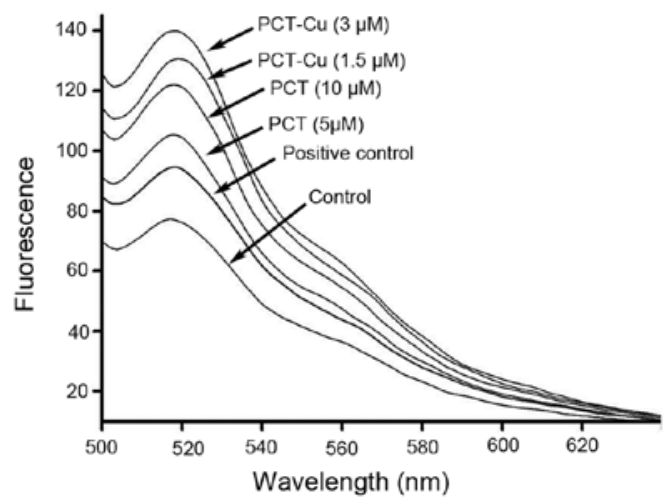

Figure 2. PCT and its copper complex (PCT-Cu) induce ROS in vitro and in vivo. (A) In vitro ROS generation in Fenton-like reaction. The ROS content was evaluated by DCF fluorescence. (B) In vivo, the ROS production in HepG2 cells after exposure of PCT and PCT-Cu. DMSO and the positive control were also included. PCT, 2-pyridinecarboxaldehyde thiosemicarbazone.

terms of fluorescent intensity, suggesting that PCT-Cu ${ }^{2+}$ could catalyze hemolysis of $\mathrm{H}_{2} \mathrm{O}_{2}$. Based on the aforementioned results, we speculated that PCT once it crosses the cell membrane may chelate $\mathrm{Fe}^{2+}$ from labile iron pool and therefore additional investigation in vivo was conducted. As expected, both PCT and PCT-Cu induced ROS generation in a concentration-dependent manner (Fig. 2B). It was noted that the fluorescent intensity of DCF from the PCT- $\mathrm{Cu}^{2+}$-treated cells was significantly greater than that of PCT, which could be due to the redox feature of $\mathrm{Cu}^{2+11+}$ complexes and the catalyzed hemolysis of $\mathrm{H}_{2} \mathrm{O}_{2}$. PCT-Cu${ }^{2+}$ can be decreased by intracellular reductants, such as glutathione, vitamin $\mathrm{C}$ or other reducing agents to form a PCT- $\mathrm{Cu}^{1+}$ complex that is able to react with $\mathrm{H}_{2} \mathrm{O}_{2}$ (13).

PCT and PCT-Cu induce ROS leading to cellular DNA fragmentation. It has been well documented that ROS cause genetic DNA breakage of host cells and induce cytotoxicity. A comet assay is a widely used technique for the evaluation of cellular DNA breakage. To further confirm the involvement of ROS in the inhibition of the proliferation of the agents, DNA integrity of HepG2 cells in the presence of PCT (or PCT-Cu) was assessed. As shown in Fig. 3A-E, typical images of migrated cell nuclei with DNA strand breaks revealed that the greater portion of the DNA had fragmented in a concentration-dependent manner following treatment with PCT compared to the control. It was noted that the PCT-Cu complex displayed a stronger effect on nuclear DNA damage compared to PCT (Fig. 3B and D, and C and E), suggesting that the copper complex caused DNA fragmentation more rapidly as it required a much lower concentration compared to PCT, which was consistent with the results from the ROS generation in vitro and in vivo (Fig. $2 \mathrm{~A}$ and $\mathrm{B}$ ).

PCT and PCT-Cu induce the depolarization of the mitochondrial membrane. In vitro ROS generation indicated that the formed PCT iron or copper complex are redox agents in a reducing environment and the newly formed reactive species in vivo could attack other biomolecules except DNA, including the mitochondrial membrane and depolarize the mitochondrial membrane and change the mitochondrial membrane potential. R123 is a fluorescent cationic dye commonly used as a mitochondrial probe. Thus PCT and PCT-Cu-induced depolarization of the mitochondrial membrane were evaluated using flow cytometry. As shown in Fig. 4, the mitochondrial fluorescent intensity from PCT-treated cells was slightly altered compared to that of the control; a 7\% increase in the M2 gate at $10 \mu \mathrm{M}$ of PCT. In contrast, $5 \mu \mathrm{M}$ of PCT-Cu treatment led to a $53 \%$ increase at the M2 gate, an 50\% increase (Fig. 4E), indicating that more cellular mitochondrial membranes were 

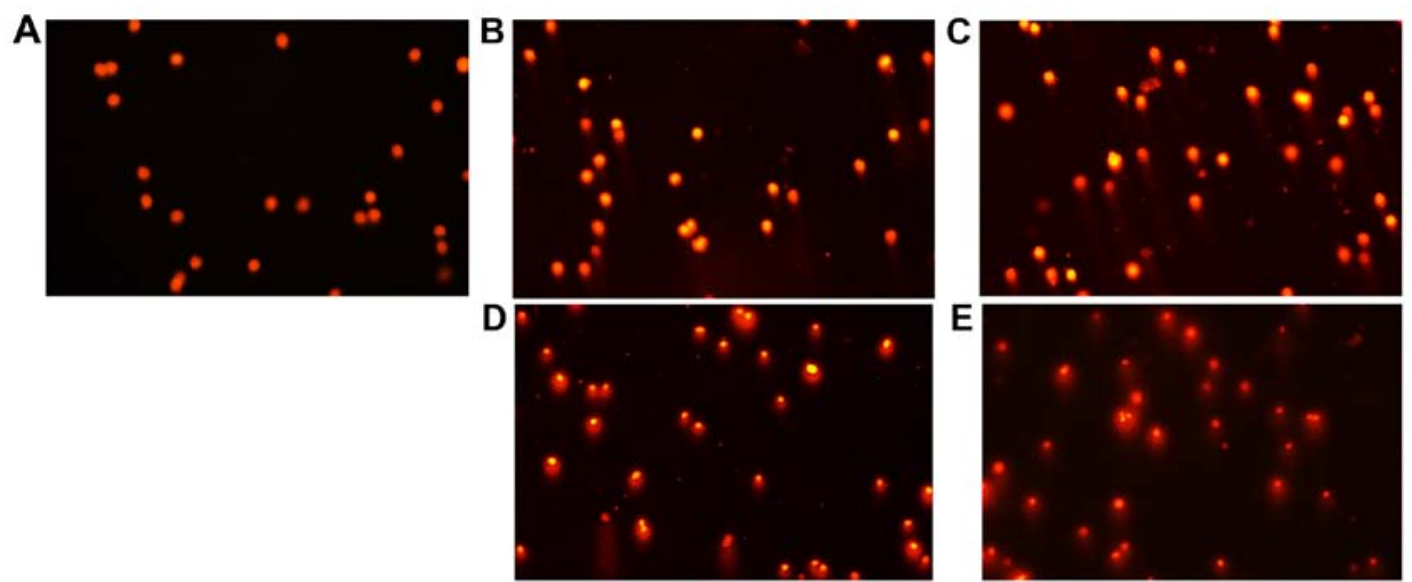

Figure 3. In vivo DNA fragmentation (comet tail) is caused by PCT and its copper complex (PCT-Cu). (A) Control, (B) $12 \mu \mathrm{M} \mathrm{PCT,} \mathrm{(C)} 25 \mu \mathrm{M}$ PCT, (D) $6 \mu \mathrm{M}$ PCT-Cu, and (E) $12 \mu \mathrm{M}$ PCT-Cu. PCT, 2-pyridinecarboxaldehyde thiosemicarbazone.
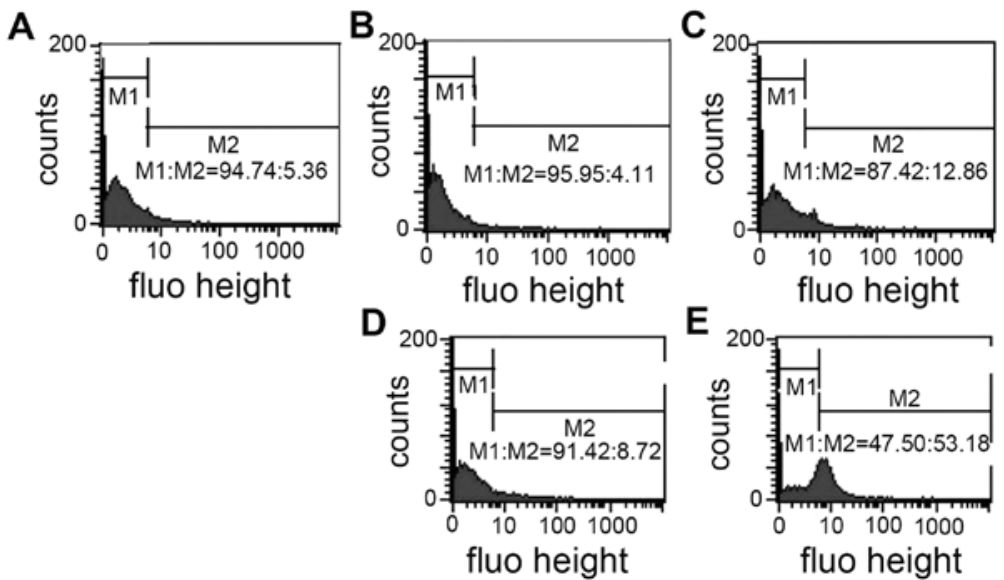

Figure 4. PCT and its copper complex (PCT-Cu) induce the depolarization of the mitochondrial membrane. (A) Control, (B) $5 \mu \mathrm{M} \mathrm{PCT,} \mathrm{(C)} 10 \mu \mathrm{M}$ PCT, (D) $2.5 \mu \mathrm{M}$ PCT-Cu and (E) $5 \mu \mathrm{M}$ PCT-Cu. PCT, 2-pyridinecarboxaldehyde thiosemicarbazone.
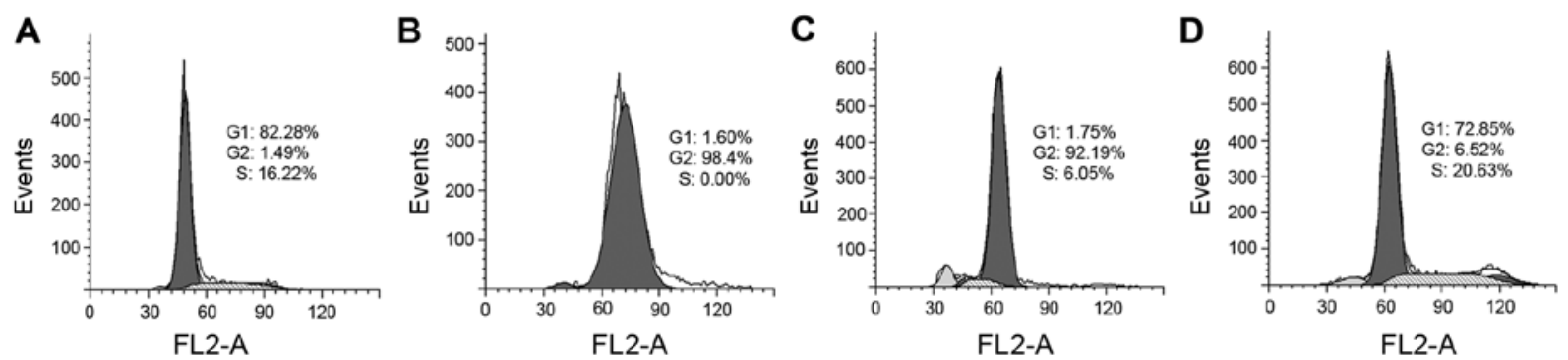

Figure 5. Cell cycle arrest is induced by PCT and its copper complex (PCT-Cu). (A) HCT-116 cells (control), (B) $5 \mu \mathrm{M} \mathrm{PCT,} \mathrm{(C)} 10 \mu \mathrm{M} \mathrm{PCT} \mathrm{and} \mathrm{(D)} 2.5 \mu \mathrm{M}$ PCT-Cu. PCT, 2-pyridinecarboxaldehyde thiosemicarbazone.

depolarized. These observations were consistent with the results of ROS production in vitro and in vivo.

PCT and PCT-Cu exhibit differential effects on the cell cycle. It has been demonstrated that ROS induce cell cycle delay and disturb cell cycle progression. We, therefore, evaluated the effect of PCT and its copper complex on cell cycle distribution using PI staining and flow cytometry. As shown in Fig. 5, PCT caused an accumulation of cells in the G2 phase. The percentage of cells at the G2 phase significantly increased from $\sim 1$ to $92 \%$ after treatment with PCT. However, in contrast to PCT, PCT-Cu was less able to disturb the cell cycle, and led to a slight increase in the percenatge (16-20\%) at the S phase. These results indicated that PCT and PCT-Cu had differential effects on the cell cycle.

PCT and its copper complex induce cellular apoptosis. ROS play a crucial role in cell growth and apoptosis. ROS production induced by PCT and PCT-Cu prompted us to investigate the underlying molecular mechanism. Generally excess ROS 

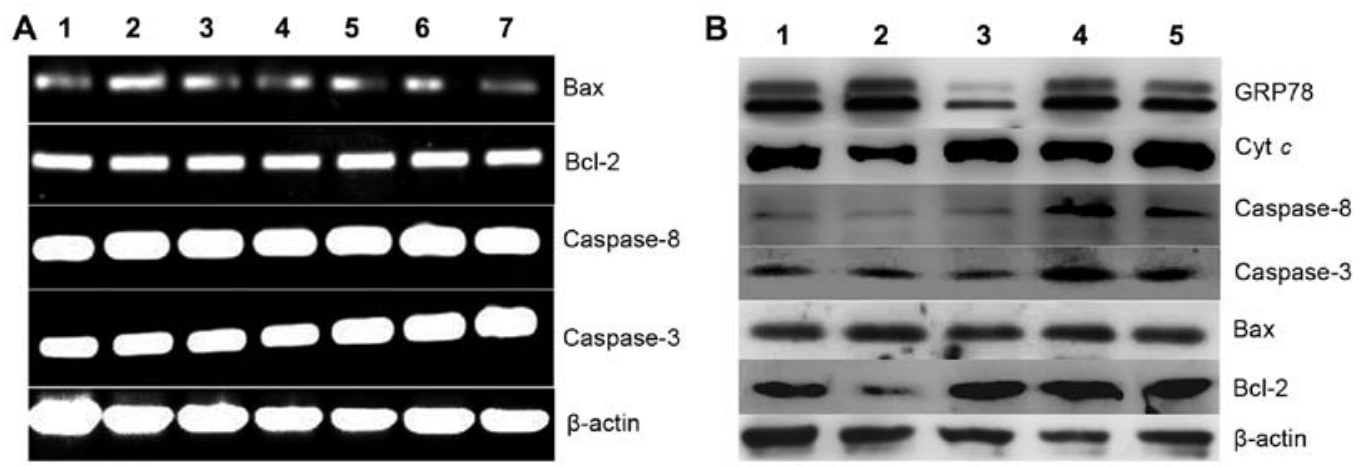

Figure 6. Gene regulation is induced by PCT and its copper complex (PCT-Cu) after 24-h treatment of HepG2 cells. (A) Gene regulation at the mRNA level: lane 1, $10 \mu \mathrm{M}$ PCT; lane 2, $5 \mu \mathrm{M}$ PCT; lane 3, $2.5 \mu \mathrm{M}$ PCT; lane 4, control; lane 5, $0.6 \mu \mathrm{M}$ PCT-Cu; lane 6, $1.2 \mu \mathrm{M}$ PCT-Cu; lane 7, 2.5 $\mu \mathrm{M}$ PCT-Cu. (B) Gene regulation at the protein level: lane 1, $10 \mu \mathrm{M}$ PCT; lane 2, $5 \mu \mathrm{M}$ PCT; lane 3, control; lane 4, 1.5 $\mu \mathrm{M}$ PCT-Cu; lane 5, $3 \mu \mathrm{M}$ PCT-Cu. PCT, 2-pyridinecarboxaldehyde thiosemicarbazone.

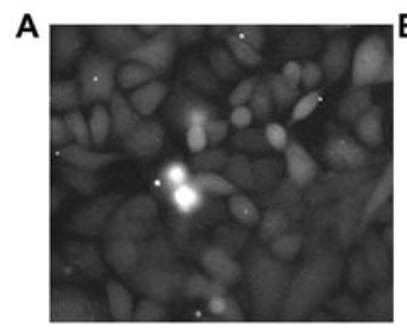

D

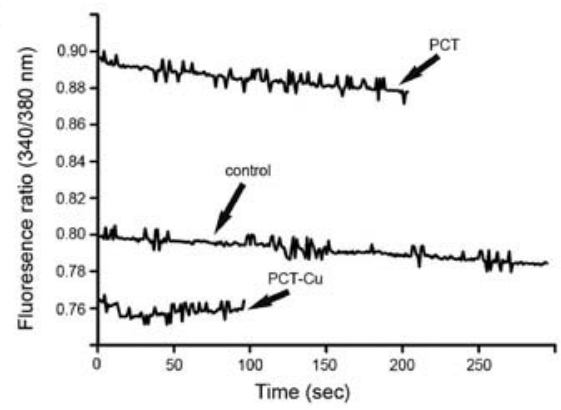

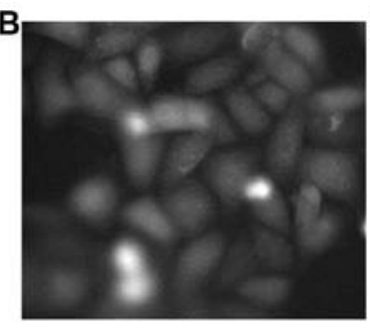

E

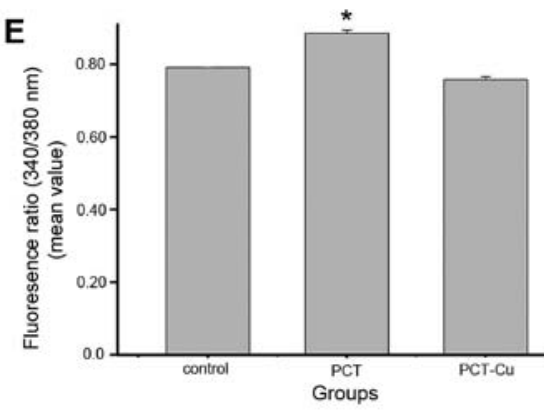

Figure 7. Static $\mathrm{Ca}^{2+}$ changes after the exposure of HepG2 cells to PCT or its copper complex (PCT-Cu). (A-C) Images in the absence and presence of PCT $(6 \mu \mathrm{M})$ or PCT-Cu $(3 \mu \mathrm{M})$ under normal microscopy. (D) Fluorescence ratio from selected cells as indicated in the images. (E) Bar chart derived from (D). * $\mathrm{p}<0.05$. PCT, 2-pyridinecarboxaldehyde thiosemicarbazone.

induce apoptosis, thus changes in the levels of apoptoticrelated genes were investigated. First we assessed whether the apoptotic genes at the transcription level were affected when the cells were exposed to the agents. As shown in Fig. 6A, caspase-3, -8, Bcl-2 and Bax displayed no evident changes, indicating that the cytotoxicity (or growth inhibition) exhibited by the agents was not via the disruption of the transcription of the investigated genes. To further seek evidence that their cytotoxicity may involve apoptosis, western blotting was performed to determine the changes in levels of the corresponding proteins. As shown in Fig. 6B, the changes in the levels of molecular markers of apoptosis, such as Bcl-2 and Bax were observed when HepG2 cells were exposed to PCT. The downregulation of Bcl-2 and upregulation of Bax clearly indicated that apoptosis involved cell growth inhibition or death. Notably in the PCT-Cu-treated cells, this situation was not evident for Bcl-2 and Bax, but the caspases (3 and 8) were upregulated, showing that caspase-dependent initiation of apoptosis may be involved. In both cases, cytoplasmic cytochrome $c$ exhibited almost no change except with the PCT-Cu treatment at a higher concentration. These results demonstrated that PCT and it copper complex displayed distinct apoptosis induction.

Oxidative stress causes calcium mobilization in the ER. Excess ROS production leads to oxidative stress, ER stress and inflammatory response, and there is cross-talk between the cellular responses (26). ER is an organelle responsible for folding and assembly of membrane and secreted proteins, synthesis of lipids and sterols, and storage of free calcium (27). GRP78 is a molecular marker of ER stress and its upregulation indicated that ER stress was induced by the agents (Fig. 6B). It has been demonstrated that ER stress can trigger calcium release from the ER and disrupt homeostasis. In order to evaluate the possibility of calcium mobilization involved in the cellular response, the cytoplasmic calcium was determined by Fura-2/AM fluorescence method. Calcium release from the ER in the static state and transient state were assessed to gain insight, as calcium signals from the static state indicate overall results, while those from the transient state indicate initial responses. Fig. 7 shows the calcium changes 

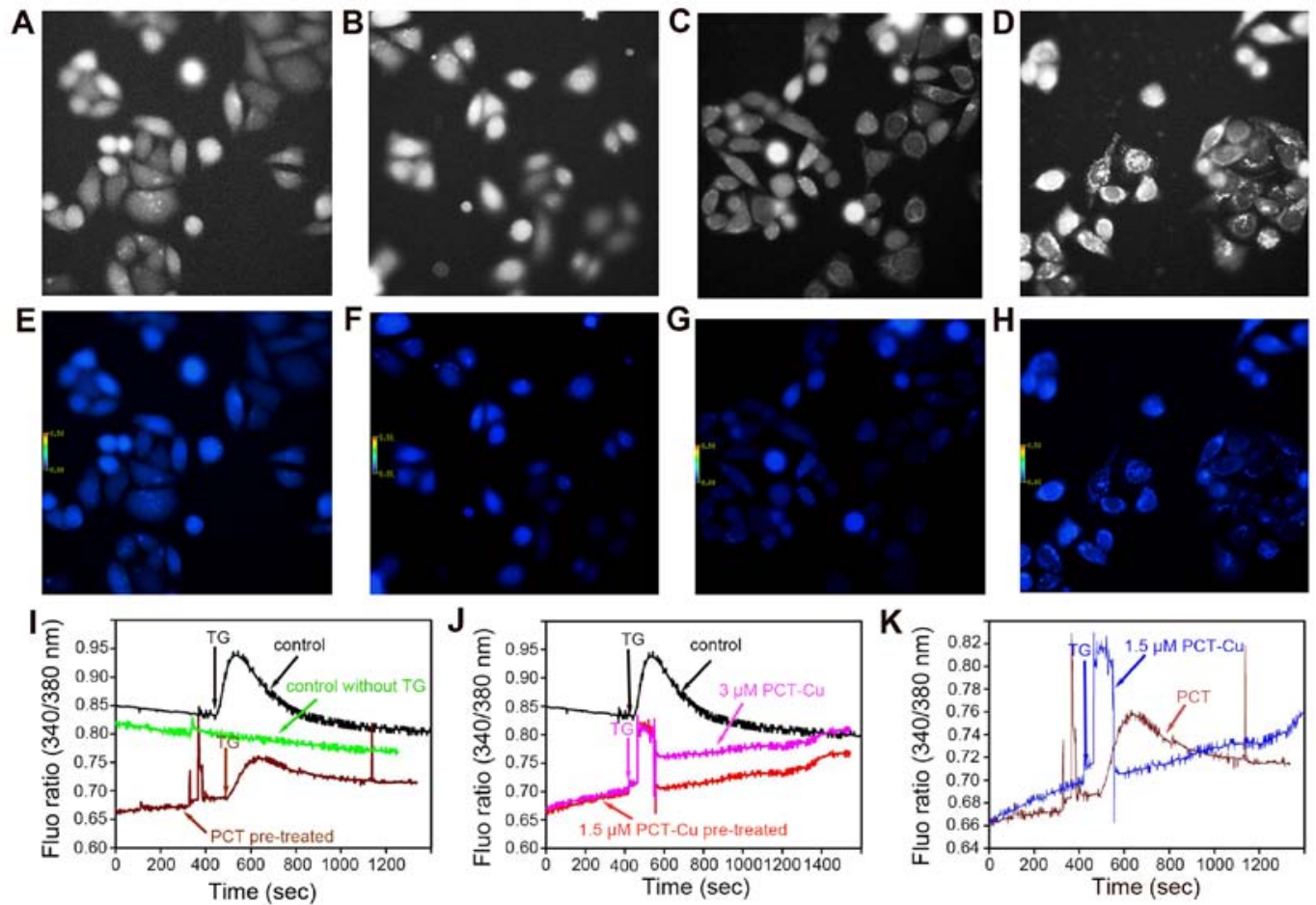

Figure 8. Transient $\mathrm{Ca}^{2+}$ changes upon thapsigargin stimulation after HepG2 cell exposure to PCT or its coppper complex (PCT-Cu). (A-D) Images of the cells in the absence or presence of PCT $(6 \mu \mathrm{M})$ or PCT-Cu $(1.5$ and $3 \mu \mathrm{M})$ under normal microscopy. (E-H) Images in the absence or presence of PCT $(6 \mu \mathrm{M})$ or PCT-Cu $(1.5$ and $3 \mu \mathrm{M})$ under fluorescence microscopy (with an optical blue color filter, not the true fluorescence color). (I) Comparison of calcium signals between the control (without drug pretreament, 35 cells selected) and PCT-pretreated cells ( 27 cells). (J) Comparison of calcium signals between the control and PCT-Cu $(1.5 \mu \mathrm{M})$ or PCT-Cu $(3 \mu \mathrm{M})$-treated cells (19 and 20 cells selected). (K) Comparison of calcium signals between PCT and PCT-Cu-pretreated cells. PCT, 2-pyridinecarboxaldehyde thiosemicarbazone.

in the static state after overnight exposure to the agents. The calcium signals were greater than that of the control for PCT, but weaker for the PCT-Cu-treated cells (Fig. 7D). Further investigation indicated that the decreased calcium signals after PCT-Cu treatment were due to serious apoptosis or death when comparing the morphology of the treated cells with the control (Fig. 7A-C). The quantitative analysis of calcium is shown in Fig. 7E. In addition, the transient changes of the calcium signals were further investigated when the cells were exposed to the agents for a short time period. As we speculated, the calcium signals from both the PCT- and PCT-Cu-treated cells continuously increased upon exposure to the agents (first period), and it appeared that more calcium was released in the PCT-Cu-treated cells (Fig. 8I and J). In contrast, the calcium signal from the control group decreased even though the fluorescent intensity was higher than that of the PCT or PCT-Cu group. The increase of calcium signals upon stimulation of the agents prompted us to probe whether the agents sensitize the cells to, thapsigargin, a $\mathrm{Ca}^{2+}$ ATPase inhibitor which stimulates calcium mobilization in the ER. Thereby, after HepG2 cells were pretreated for 5 min thapsigargin was added. As shown in Fig. 8I, PCT treatment decreased the sensitivity of thapsigargin stimuli. In contrast to PCT, PCT- $\mathrm{Cu}$ enhanced the sensitivity of thapsigargin stimuli. The difference induced by PCT and PCT-Cu in the sensitivity of thapsigargin stimuli is shown in Fig. $8 \mathrm{~K}$. Clearly, both PCT and PCT-Cu induced transient calcium release, but the latter was stronger, in correlation to their ROS production.

\section{Discussion}

Anticancer drug treatment frequently causes caspase-dependent apoptosis, ROS generation and mitochondrial damage (28). Induced apoptosis in most of the cancer cells is correlated with excess ROS formation $(29,30)$. Thiosemicarbazones have potential metal chelation ability, and the iron chelates are redox-active and produce ROS in most cases (31). PCT as the Dp44mT analog, induced ROS formation in vitro and in vivo (Fig. 2), implying the possibility that PCT participated in a Fenton-like reaction chelating iron from the labile iron pool (32). The PCT copper complex (PCT-Cu) also exhibited significant and potent ROS generation in vivo (Fig. 2B) due to the easy transition of $\mathrm{Cu}^{2+/ 1+}$ in the cellular environment, which produced a redox cycle to generate ROS as previously described (12). In addition, the catalytic activity in hemolysis of $\mathrm{H}_{2} \mathrm{O}_{2}$ may be a contributive factor to ROS (Fig. 2A). In this study, the ROS output induced by PCT and PCT-Cu appeared to be correlated to their growth inhibition, a situation which has been observed in other studies $(33,34)$. Cell cycle arrest is another mechanism exhibited by most anticancer drugs. PCT caused HCT-116 cell delay at the G2/M phase in an ROS-dependent manner $(35,36)$, but PCT-Cu had a different effect on cell cycle progression. It induced an increase in the $S$ phase population (Fig. 5), suggesting that chelation altered their effect. Excess ROS production disrupts homeostasis of cellular redox, causing oxidative stress leading to cellular component-damage. The DNA fragmentation in the present study was correlated to 
their ability in ROS generation (Fig. 3). Cell death may occur in diverse manners. Apoptosis and necrosis, and the evaluation of apoptotic genes both at the mRNA and protein level provide important information concerning the mechanism (37). PCT and PCT-Cu did not disturb the transcription of apoptotic genes (Fig. 6A), but did disturb the transcription of the related proteins. It has been demonstrated that the Bcl-2-family of proteins plays central roles in cell death regulation that encompass apoptosis, necrosis and autophagy. Bax as a pro-apoptotic protein induces mitochondrial outer membrane permeabilization, causing caspase activation, whereas Bcl-2 as an antiapoptotic protein has the opposing function of Bax (38). In PCT-treated HepG2 cells, the increased Bax and decreased Bcl-2 levels compared to that of the control were observed, indicating that apoptosis was involved. Notably, caspase- 3 and -8 exhibited no significant changes in the treated and control groups (Fig. 6B), implying that PCT was less effective on mitochondrial outer membrane permeabilization, a finding which was further supported by the assay of mitochondrial membrane permeabilization (Fig. 4A-C). A similar situation was also observed in another study (39). In contrast, in PCT-Cu-treated cells, Bax and Bcl-2 displayed no evident change, while caspase- 3 and -8 were significantly increased, indicating that PCT-Cu has the ability to affect mitochondrial membrane permeabilization, a fact which was further supported by the assay of mitochondrial membrane permeabilization (Fig. 4A, D and E). The aforementioned data indicated that there was a distinct difference in the induction of apoptosis between PCT and PCT-Cu. Generally apoptosis is not linked with total caspase- 3 and -8 because their activity can be affected by phosphorylation of specific kinases, such as the p38 mitogen-activated protein kinase $(40,41)$. Therefore PCT- $\mathrm{Cu}$ induced caspase- 8 and -3 activation possibly via the mitochondrial pathway (42). This was supported by an increase of mitochondrial cytochrome $c$ (cyt $c$ ) as the depolarization of the mitochondrial membrane (or changes in permeability), causes cytochrome $c$ to leak into the cytosol and initiate activation of a cascade of caspases (43). In our experiment, the increase of cytochrome $c$ in the PCT-Cu-treated HepG2 cells was correlated with the increase of caspase- 3 and -8 .

Protein folding and generation of ROS in the ER are closely linked events (44). PCT- and PCT-Cu-induced ROS increase in vivo implied that oxidative stress occurred. Persistent oxidative stress led to the oxidation of proteins or protein misfolding, that initiated activation of the UPR and ER stress. GRP78 is a molecular marker of ER stress and its overexpression further confirmed that ER stress occured in a ROS-dependent manner (Fig. 6B). The ER is both a unique place for protein folding and is also the primary $\mathrm{Ca}^{2+}$-storage organelle in the cell. Protein-folding and protein chaperone all require higher levels of ER intraluminal calcium. Thus, calcium release leads to the malfunction of the ER. The antitumor mechanism of the involvement of iron chelators in ER stress has been demonstrated $(45,46)$. But in ER stress, how iron chelators influence calcium storage in the ER has received less attention. In this study, we preliminarily explored the relationship between ER stress and cy toplasmic calcium. Upon exposure to the investigated agents, our data showed that the transient stimuli of PCT or PCT-Cu did not cause significant calcium release, but gradually increased (Fig. 8I and J). This may reflect that the uptake of the agents was slow, or the absence of a specific receptor and channel because extended cell exposure to these agents, revealed that the calcium signal significantly increased (Fig. 7D). Both PCT and PCT-Cu induce calcium release as reported in curcumin-induced cell death (47). To examine whether PCT (or PCT-Cu) affected the target thapsigargin, the HepG2 cells were pretreated with the agents for $5 \mathrm{~min}$. Then thapsigargin stimulated the Fura-2/AM loaded cells. Notably PCT attenuated the sensitivity of thapsigargin (Fig. 8I), but PCT-Cu had the reverse action and enhanced calcium release (Fig. 8J), indicating that the increased calcium flux may contribute to their cytotoxicity. However caution should be used when drawing this conclusion because there was ER stress in the present study and whether the calcium mobilization from the ER can inhibit cell growth without ER stress is unknown and requires further research.

In conclusion, in this study we evaluated the cytotoxicity and mechanism of PCT and PCT-Cu. The $\mathrm{IC}_{50}$ differences in the investigated cell lines were indicative of drug selectivity, but the copper chelate displayed enhanced antitumor behavior. DNA fragmentation, ER stress and apoptosis were all indications that ROS production was the most significant factor. Notably our findings suggested that the calcium mobilization in the ER was also involved in the cytotoxicity exhibited by the agents. Cell cycle analysis demonstrated that PCT and PCT-Cu had differential effects on cell cycle progression, supporting that PCT was not involved in the inhibition of ribonucleic reductase. Therefore, the proliferation inhibition of PCT and PCT-Cu may involve diverse mechanisms.

\section{Acknowledgements}

The present study was supported by grants awarded by the Natural Science Foundation of China (no. 21571153), the Henan Science and Technology Agency (nos. 114300510012, 132102310250 and 152300410118$)$ and the Henan Educational Administration (15A416009).

\section{References}

1. Husain K, Bhat AR and Azam A: New Pd(II) complexes of the synthesized 1- $N$-substituted thiosemicarbazones of 3-indole carboxaldehyde: Characterization and antiamoebic assessment against $E$. histolytica. Eur J Med Chem 43: 2016-2028, 2008.

2. Rodríguez-Argüelles MC, Tourón-Touceda P, Cao R, García-Deibe AM, Pelagatti P, Pelizzi C and Zani F: Complexes of 2-acetyl- $\gamma$-butyrolactone and 2-furancarbaldehyde thiosemicarbazones: Antibacterial and antifungal activity. J Inorg Biochem 103: 35-42, 2009.

3. Quach P, Gutierrez E, Basha MT, Kalinowski DS, Sharpe PC, Lovejoy DB, Bernhardt PV, Jansson PJ and Richardson DR: Methemoglobin formation by triapine, di-2-pyridylketone-4,4-dimethyl-3-thiosemicarbazone (Dp44mT), and other anticancer thiosemicarbazones: Identification of novel thiosemicarbazones and therapeutics that prevent this effect. Mol Pharmacol 82: 105-114, 2012.

4. García-Tojal J, García-Jaca J, Cortés R, Rojo T, Urtiaga KM, Arriortua IM: Synthesis and spectroscopic properties of two pyridine-2-carbaldehyde thiosemicarbazonecopper(II) compounds: $\left[\mathrm{CuX}_{2}\left(\mathrm{C}_{7} \mathrm{H}_{8} \mathrm{~N}_{4} \mathrm{~S}\right)\right] \cdot \mathrm{H}_{2} \mathrm{O}(\mathrm{X}=\mathrm{Br}, \mathrm{Cl})$. Crystal structure of the bromo complex. Inorg Chim Acta 249: 25-32, 1996.

5. Chandra S, Parmar S and Kumar Y: Synthesis, spectroscopic, and antimicrobial studies on bivalent zinc and mercury complexes of 2-formylpyridine thiosemicarbazone. Bioinorg Chem Appl 2009: 851316, 2009. 
6. Baldini M, Belicchi-Ferrari M, Bisceglie F, Capacchi S, Pelosi G and Tarasconi P: Zinc complexes with cyclic derivatives of alpha-ketoglutaric acid thiosemicarbazone: Synthesis, X-ray structures and DNA interactions. J Inorg Biochem 99: 1504-1513, 2005.

7. Pelosi G: Thiosemicarbazone metal complexes: from structure to activity. Open Crystallogr J 3: 16-28, 2010.

8. Cabrera M, Gomez N, Remes Lenicov F, Echeverría E, Shayo C, Moglioni A, Fernández N and Davio C: G2/M cell cycle arrest and tumor selective apoptosis of acute leukemia cells by a promising benzophenone thiosemicarbazone compound. PLoS One 10: $\mathrm{e} 0136878,2015$.

9. Shao J, Zhou B, Di Bilio AJ, Zhu L, Wang T, Qi C, Shih J and Yen Y: A Ferrous-Triapine complex mediates formation of reactive oxygen species that inactivate human ribonucleotide reductase. Mol Cancer Ther 5: 586-592, 2006.

10. Cao SS and Kaufman RJ: Endoplasmic reticulum stress and oxidative stress in cell fate decision and human disease. Antioxid Redox Signal 21: 396-413, 2014.

11. Hancock CN, Stockwin LH, Han B, Divelbiss RD, Jun JH, Malhotra SV, Hollingshead MG and Newton DL: A copper chelate of thiosemicarbazone NSC 689534 induces oxidative/ER stress and inhibits tumor growth in vitro and in vivo. Free Radic Biol Med 50: 110-121, 2011.

12. Lovejoy DB, Jansson PJ, Brunk UT, Wong J, Ponka P and Richardson DR: Antitumor activity of metal-chelating compound Dp44mT is mediated by formation of a redox-active copper complex that accumulates in lysosomes. Cancer Res 71: 5871-5880, 2011.

13. Kowol CR, Heffeter P, Miklos W, Gille L, Trondl R, Cappellacci L, Berger W and Keppler BK: Mechanisms underlying reductant-induced reactive oxygen species formation by anticancer copper(II) compounds. J Biol Inorg Chem 17: 409-423, 2012.

14. Kowol CR, Trondl R, Arion VB, Jakupec MA, Lichtscheidl I and Keppler BK: Fluorescence properties and cellular distribution of the investigational anticancer drug triapine (3-aminopyridine-2-carboxaldehyde thiosemicarbazone) and its zinc(II) complex. Dalton Trans 39: 704-706, 2010.

15. Trondl R, Flocke LS, Kowol CR, Heffeter P, Jungwirth U, Mair GE, Steinborn R, Enyedy ÉA, Jakupec MA, Berger W, et al: Triapine and a more potent dimethyl derivative induce endoplasmic reticulum stress in cancer cells. Mol Pharmacol 85: 451-459, 2014.

16. Berridge MJ: Elementary and global aspects of calcium signalling. J Physiol 499: 291-306, 1997.

17. Berridge MJ: Inositol trisphosphate and calcium signalling. Nature 361: 315-325, 1993

18. Rogers TB, Inesi G, Wade R and Lederer WJ: Use of thapsigargin to study $\mathrm{Ca}^{2+}$ homeostasis in cardiac cells. Biosci Rep 15 : 341-349, 1995

19. Chandra S, Raizada S, Tyagi M and Sharma PK: Spectroscopic and biological approach of $\mathrm{Ni}(\mathrm{II})$ and $\mathrm{Cu}(\mathrm{II})$ complexes of 2-pyridinecarboxaldehyde thiosemicarbazone. Spectrochim Acta A Mol Biomol Spectrosc 69: 816-821, 2008.

20. Chen D, Cui QC, Yang H, Barrea RA, Sarkar FH, Sheng S, Yan B, Reddy GP and Dou QP: Clioquinol, a therapeutic agent for Alzheimer's disease, has proteasome-inhibitory, androgen receptor-suppressing, apoptosis-inducing, and antitumor activities in human prostate cancer cells and xenografts. Cancer Res 67: 1636-1644, 2007

21. Huang T, Li C, Sun X, Zhu Z, Fu Y, Liu Y, Yuan Y, Li S and $\mathrm{Li} \mathrm{C}$ : The antitumor mechanism of di-2-pyridylketone 2-pyridine carboxylic acid hydrazone and its copper complex in ROS generation and topoisomerase inhibition, and hydrazone involvement in oxygen-catalytic iron mobilization. Int J Oncol 47: $1854-1862,2015$

22. Singh NP, McCoy MT, Tice RR and Schneider EL: A simple technique for quantitation of low levels of DNA damage in individual cells. Exp Cell Res 175: 184-191, 1988.

23. Fu Y, Zhang Y, Zhou SF, Liu Y, Wang J, Wang Y, Lu C and Li C: Effects of substitution of carboxyl with hydrazide group on position 3 of ciprofloxacin on its antimicrobial and antitumor activity. Int J Pharmacol 9: 416-429, 2013.

24. Wang J, Wang Y, Wang Y, Wang R, Zhang Y, Zhang Q and Lu C: Contribution of $\alpha 4 \beta 2 \mathrm{nAChR}$ in nicotine-induced intracellular calcium response and excitability of MSDB neurons. Brain Res 1592: 1-10, 2014.

25. Liu MC, Lin TS and Sartorelli AC: Synthesis and antitumor activity of amino derivatives of pyridine-2-carboxaldehyde thiosemicarbazone. J Med Chem 35: 3672-3677, 1992.
26. Zhang K: Integration of ER stress, oxidative stress and the inflammatory response in health and disease. Int J Clin Exp Med 3: 33-40, 2010

27. Gething MJ and Sambrook J: Protein folding in the cell. Nature 355: 33-45, 1992.

28. Brodská B and Holoubek A: Generation of reactive oxygen species during apoptosis induced by DNA-damaging agents and/or histone deacetylase inhibitors. Oxid Med Cell Longev 2011: 253529, 2011.

29. Sun Y, Huang L, Mackenzie GG and Rigas B: Oxidative stress mediates through apoptosis the anticancer effect of phospho-nonsteroidal anti-inflammatory drugs: Implications for the role of oxidative stress in the action of anticancer agents. J Pharmacol Exp Ther 338: 775-783, 2011.

30. Rigas B and Sun Y: Induction of oxidative stress as a mechanism of action of chemopreventive agents against cancer. $\mathrm{Br} \mathrm{J}$ Cancer 98: 1157-1160, 2008.

31. Jansson PJ, Hawkins CL, Lovejoy DB and Richardson DR: The iron complex of $\mathrm{Dp} 44 \mathrm{mT}$ is redox-active and induces hydroxyl radical formation: An EPR study. J Inorg Biochem 104: 1224-1228, 2010

32. Kakhlon O and Cabantchik ZI: The labile iron pool: Characterization, measurement, and participation in cellular processes(1). Free Radic Biol Med 33: 1037-1046, 2002.

33. Preza AM, Jaramillo ME, Puebla AM, Mateos JC, Hernández R and Lugo E: Antitumor activity against murine lymphoma L5178Y model of proteins from cacao (Theobroma cacao L.) seeds in relation with in vitro antioxidant activity. BMC Complement Altern Med 10: 61, 2010.

34. Vandamme M, Robert E, Lerondel S, Sarron V, Ries D, Dozias S, Sobilo J, Gosset D, Kieda C, Legrain B, et al: ROS implication in a new antitumor strategy based on non-thermal plasma. Int J Cancer 130: 2185-2194, 2012.

35. Zhang X, Chen M,Zou P, Kanchana K, Weng Q, Chen W, Zhong P, Ji J, Zhou H, He L, et al: Curcumin analog WZ35 induced cell death via ROS-dependent ER stress and G2/M cell cycle arrest in human prostate cancer cells. BMC Cancer 15: 866, 2015.

36. Guo J, Wu G, Bao J, Hao W, Lu J and Chen X: Cucurbitacin B induced ATM-mediated DNA damage causes G2/M cell cycle arrest in a ROS-dependent manner. PLoS One 9: e88140, 2014.

37. Vandaele L, Goossens K, Peelman L and Van Soom A: mRNA expression of $\mathrm{Bcl}-2$, Bax, caspase-3 and -7 cannot be used as a marker for apoptosis in bovine blastocysts. Anim Reprod Sci 106: 168-173, 2008.

38. Yip KW and Reed JC: Bcl-2 family proteins and cancer. Oncogene 27: 6398-6406, 2008.

39. Liang Y, Yan C and Schor NF: Apoptosis in the absence of caspase 3. Oncogene 20: 6570-6578, 2001.

40. Alvarado-Kristensson M, Melander F, Leandersson K, Rönnstrand L, Wernstedt C and Andersson T: p38-MAPK signals survival by phosphorylation of caspase- 8 and caspase-3 in human neutrophils. J Exp Med 199: 449-458, 2004.

41. Voss OH, Kim S, Wewers MD and Doseff AI: Regulation of monocyte apoptosis by the protein kinase Cdelta-dependent phosphorylation of caspase-3. J Biol Chem 280: 17371-17379, 2005.

42. Liu J, Uematsu H, Tsuchida N and Ikeda MA: Essential role of caspase-8 in p53/p73-dependent apoptosis induced by etoposide in head and neck carcinoma cells. Mol Cancer 10: 95, 2011.

43. Cai J, Yang J and Jones D: Mitochondrial control of apoptosis: The role of cytochrome $c$. Biochim Biophys Acta 1366: 139-149, 1998.

44. Malhotra JD and Kaufman RJ: Endoplasmic reticulum stress and oxidative stress: A vicious cycle or a double-edged sword? Antioxid Redox Signal 9: 2277-2293, 2007.

45. Kim JL, Lee DH, Na YJ, Kim BR, Jeong YA, Lee SI, Kang S, Joung SY, Lee SY, Oh SC, et al: Iron chelator-induced apoptosis via the ER stress pathway in gastric cancer cells. Tumour Biol 37: 9709-9719, 2016

46. Lane DJ, Mills TM, Shafie NH, Merlot AM, Saleh Moussa R, Kalinowski DS, Kovacevic Z and Richardson DR: Expanding horizons in iron chelation and the treatment of cancer: Role of iron in the regulation of ER stress and the epithelial-mesenchymal transition. Biochim Biophys Acta 1845: 166-181, 2014.

47. Moustapha A, Pérétout PA, Rainey NE, Sureau F, Geze M, Petit JM, Dewailly E, Slomianny C and Petit PX: Curcumin induces crosstalk between autophagy and apoptosis mediated by calcium release from the endoplasmic reticulum, lysosomal destabilization and mitochondrial events. Cell Death Dis 1: 15017, 2015. 